\title{
Impact of Videoconference with Native English Speakers on Chinese EFL Learners' Oral Competence and Self-Confidence
}

\author{
Ruiling Lu1, Timothy A. Goodale ${ }^{2}$, Yanbing Guo $^{3}$ \\ ${ }^{1}$ Department of Education, Taiyuan Normal University, Taiyuan, China \\ ${ }^{2}$ Department of Education, College of Coastal Georgia, Brunswick, USA \\ ${ }^{3}$ Department of English, Xiamen Academy of Educational Science, Xiamen, China \\ Email: ruilinglu9@hotmail.com
}

Received October 2013

\begin{abstract}
This study presents an educational collaborative project between two colleges in the United States and China. Forty-five Chinese pre-service teachers and 5 American undergraduates participated in the project which involved a 10-week online synchronous videoconference between the participants. The project aimed at improving Chinese EFL learners' English oral skills as well as their confidence in teaching English language in future. Quasi-experiment design was employed to evaluate the effectiveness of the project. Results showed that online synchronous videoconference with native English speakers did have positive impacts on Chinese participants' English pronunciation and oral fluency $\&$ coherent. No significant difference was found in confidence measures. The outcomes of the project contribute to the relevant literature with an applicable and low-cost English language training model for EFL learners.
\end{abstract}

\section{Keywords}

Synchronous Video Conference; EFL Learners; Oral Skills; Confidence

\section{Introduction}

The role of China within the global economy is growing rapidly at an accelerating rate and constantly expanding. This has given rise to a pressing demand of Chinese people for English proficiency. In conjunction with this growth and demonstrated importance, Chinese students are seeking to improve their English competence to better communicate in a global context. However, circumstances are not optimistic. Though English language learning is one of the core courses in elementary, secondary, and higher education, Chinese EFL (English as a foreign language) learners are found still pretty weak in their English proficiency, especially in listening and speaking ability. According to a recent news report, Chinese ranks the second to last in English proficiency among 12 Asian countries [1]. Various reasons account for this phenomenon. First, inadequate attention is given 
to listening and speaking in English instruction, especially at Chinese secondary schools because of "teachto-test default policy" (these two skills are not tested in high school and college entrance examinations in most parts of China). Second, almost all English language instruction is conducted in Chinese due to lack of quality English language instructors at all educational levels. This is especially true in rural and developing regions of China. Third, as EFL learners, they have limited input and output of English language both inside and outside classroom as a result of large class size and lack of English learning environment. Last, most Chinese EFL learners are not confident in their English listening and speaking skills as they do not have many opportunities to use English language in authentic settings.

With the problem becoming more and more salient, many English language institutions in China try to improve the situation by hiring native English speakers with the intention of creating more access to high quality English teachers and better English learning environment. This strategy works to certain extent. Unfortunately due to a small number of available native English speakers and high cost of hiring them, this resource is in fact not feasible to most educational institutions.

Such a problem is not unique to China. Most EFL countries have been facing similar challenges. In an attempt to address this issue, many educators and researchers resort to information technology. With the rapid development of online resources and easy accessibility of Internet on campus, computer-assisted language learning (CALL) has become more and more prevalent worldwide [2-4]. Roed suggested that virtual communication may create a more relaxed and stress-free atmosphere than classrooms, and thus leading to more language production [5]. It is also found that use of online tools is especially helpful with listening and speaking skills of English learners [6]. Mixed research results have been reported on student self-confidence and learning modalities (face-to-face vs. online). Wu concluded from a survey data analysis that students felt more comfortable and confident in their language skills via online authentic interaction with native English speaker [7]. Whereas Kissau deposited that teacher candidates completed face-to-face L2 courses were more confident in teaching L2 learners than their counterparts who completed the L2 courses online [8].

Building on the previous research on computer-based language learning and recent Web 2.0 interactive tools, the authors of the paper designed an online educational collaborative language learning project between two colleges in the United States and China. The foundation of this research consists of weekly live videoconference between Chinese EFL learners who are pre-service teachers and their American peers who are native English speakers. The purpose of this project was to help Chinese pre-service English teachers improve their competence in English oral skills and raise their confidence in teaching English language in future by creating more authentic, interactive and stress-free cyber English learning environment. These dimensions were selected because it has long been noted that self-confidence is positively related to task performance and actual language ability [9]. In addition, though bunch of literature state that videoconference with native English speakers result in improved English ability, no research has dealt with different dimensions of English oral ability. This study intended to evaluate the effectiveness of the project by examining the impacts of online synchronous videoconference with native English speakers on Chinese pre-service English teachers' oral English skills in relation to Fluency \& Coherence, Lexical Resource, Grammatical Range \& Accuracy, and Pronunciation as well as their confidence in teaching English language in future. The study was guided by the following research questions:

- Does synchronous videoconference with native English speakers have positive impacts on the four dimensions of English oral skills of Chinese pre-service English teachers?

- Does synchronous videoconference with native English speakers help Chinese pre-service English teachers become more confident in teaching English language in future?

\section{Method}

\subsection{Research Design}

This study employed a quasi-experimental research design that utilized non-equivalent groups. Two groups of Chinese college students with similar education background were compared for competence in oral English and confidence in teaching English language in future.

\subsection{Participants}

This study involved a total of 45 undergraduates at Taiyuan Normal University in mainland China. The partici- 
pants were a class of sophomores enrolled in a teacher education program and seeking certification to teach English at elementary level (pre-service English teachers). Twenty-five students in this class were randomly assigned to the experimental group while the other 20 students were assigned to the control group.

Native English speakers who served as peer English instructors for this project were selected from the College of Coastal Georgia in the United States. Selection of the peer instructors were conducted through an application process that was targeted towards pre-service teachers seeking certification in English or language arts. Five instructors were chosen at random upon initial screening of basic qualifications.

The 25 Chinese students that were identified in the experimental group were randomly assigned into groups of five and assigned to a single American peer instructor. However, interaction and instruction occurred on a one to one basis within the group.

\subsection{Procedure}

The treatment of this study consisted of a 10 -week educational project that includes weekly synchronous videoconferencing sessions between Chinese pre-service English teachers and their American peers. The Chinese project participants were assigned a speech topic for each conferencing session which was conducted and evaluated in a similar manner to the IELTS (International English Language Testing System) oral examination.

On each videoconferencing session, American peer instructors "called" their cohort of 5 Chinese students. The live video conferencing sessions had scripted open ended prompts/questions for the American instructors to ask of their Chinese students. These sessions were recorded and later evaluated by the project personnel. Immediate peer feedback on how well each student performed during the conversation and how to improve oral skills were provided by the American instructors to their Chinese students. These live video conferencing sessions took place once a week. Each session lasted 100 minutes (equal to one block course schedule), and every Chinese participant had approximate 20 minutes to talk/converse with their American peer instructors.

While the experiment group was having live videoconference with their American peers, the control group took the English speaking course delivered by the course instructor in a regular classroom setting, which also lasted 100 minutes. The topic of each class session was same as that of the experiment group.

Both groups were pre- and post tested on their oral English skills in four dimensions: Fluency \& Coherence, Lexical Resource, Grammatical Range \& Accuracy, and Pronunciation. Additionally, attitudinal surveys on participants' confidence in various aspects of teaching English language in future were administered to all participants at the end of the treatment to determine if significant difference occurred between the groups.

\subsection{Materials and Instruments}

The digital nature of this project required several technological items. American peer instructors were required to have a personal computer with internet access, web camera, microphone and access to a web conference and course management platform (Skype and Vodburner). The treatment group had the synchronous videoconferencing sessions at the university computer lab with same facilities and access.

Chinese students' oral skills as reflected in the pre-and post tests were measured on a speaking assessment rubric with four dimensions (Fluency \& Coherence, Lexical Resource, Grammatical Range \& Accuracy, and Pronunciation) which was based within the oral examination components and assessment criteria of the IELTS examination. The total score of the pre-and post test measure is 100 points, with each dimension weighing 25 points. Items on the attitudinal survey measuring participant confidence in teaching English in future were derived and modified from Jeong-Ah Lee's surveys on English Teaching Confidence, Attitudes toward English and English Language Speaking Proficiency [10]. The survey items were scored in 5-point Likert Scale, with 1 indicating lowest confidence, and 5 the highest.

\subsection{Data Collection and Analysis}

Data collection started with the pre-test of English oral skills for all participants at the beginning of the treatment. The post-test along with an altitudinal survey on participants' confidence in teaching English were administered one week after the treatment ended.

One-way Analysis of Co-Variance (ANCOVA) was conducted to examine students' performance on the preand post-tests to estimate the difference between the groups on the post-test after adjusting for differences on the 
pre-test. A $t$-Test was conducted on students' responses to the post attitudinal survey to determine statistically significant differences in participants' confidence in teaching English language.

\section{Results}

\subsection{Participant Oral Skills}

To answer the first research question: "Does synchronous videoconference with native English speakers have positive impacts on the four dimensions of English oral skills of Chinese pre-service English teachers", one-way analysis of covariance (ANCOVA) was conducted on participant pre-and post-test performance. The independent variable, the treatment, included two levels: online synchronous video conference and traditional classroom instruction. The dependent variable was English oral skills as reflected in four dimensions (Fluency \& Coherence, Lexical Resource, Grammatical Range \& Accuracy, and Pronunciation). The covariate was the pre-test English oral skills measured on the four dimensions before the treatment. ANCOVA was significant on three of the four measures and the strength of relationship between the independent variable and dependent variables was strong: on Fluency \& Coherence, F $(1,42)=18.40$, MSE $=0.48, \mathrm{p}<0.01, \eta^{2}=0.31$; on Grammatical Range \& Accuracy, F $(1,42)=6.37, \mathrm{MSE}=0.33, \mathrm{p}=0.02, \eta^{2}=0.13$; on Pronunciation, $\mathrm{F}(1,42)=19.96$, MSE $=0.41, \mathrm{p}$ $<0.01, \eta^{2}=0.32$. No significant difference was found on the measure of Lexical Resource (see Table 1).

The means of the post-test scores on the four measures adjusted for initial differences were presented in Table 2 and Figure 1. The descriptive statistics showed that the experiment group scored higher than their counterparts in the control group on the measures of Fluency \& Coherence, and Pronunciation, whereas the control group had better performance on the measure of Grammatical Range \& Accuracy. The two groups scored closely on the measure of Lexical Resource, with the control group scored a little higher. These results indicated that online synchronous videoconference with native English speakers had strong positive impacts on participants' English oral skills in terms of fluency, coherence, and pronunciation. On the other hand, traditional classroom English instruction conducted by native Chinese instructor worked better on the dimension of grammar. The two instructional approaches worked equally well in lexical resource.

Table 1. ANCOVA of posttest oral skills.

\begin{tabular}{cccccc}
\hline Variable & $\boldsymbol{d} \boldsymbol{f}$ & MSE & $\mathbf{F}$ & $\mathbf{p}$ & $\boldsymbol{\eta}^{2}$ \\
\hline Fluency \& Coherence & 1 & 0.48 & 18.40 & 0.00 & 0.31 \\
Lexical Resource & 1 & 0.97 & 0.27 & 0.61 & 0.01 \\
Grammar & 1 & 0.33 & 6.37 & 0.02 & 0.13 \\
Pronunciation & 1 & 0.41 & 19.96 & 0.00 & 0.32 \\
\hline
\end{tabular}

Table 2. Means of posttest oral skill scores by group.

\begin{tabular}{cccccc}
\hline Variable & Group & Unadjusted Means & SD & Adjusted Means & SE \\
\hline \multirow{2}{*}{ Fluency \& Coherence } & Experiment & 20.80 & 1.83 & 21.17 & 0.14 \\
& Control & 20.70 & 1.95 & 20.24 & 0.16 \\
Lexical & Experiment & 20.76 & 1.64 & 20.82 & 0.20 \\
Resource & Control & 21.05 & 1.57 & 20.97 & 0.22 \\
& Experiment & 20.80 & 1.65 & 20.78 & 0.11 \\
Grammar & Control & 21.20 & 1.40 & 21.22 & 0.13 \\
& Experiment & 20.73 & 1.64 & 21.11 & 0.13 \\
Pronunciation & Control & 20.60 & 1.49 & 20.59 & 0.15 \\
\hline
\end{tabular}




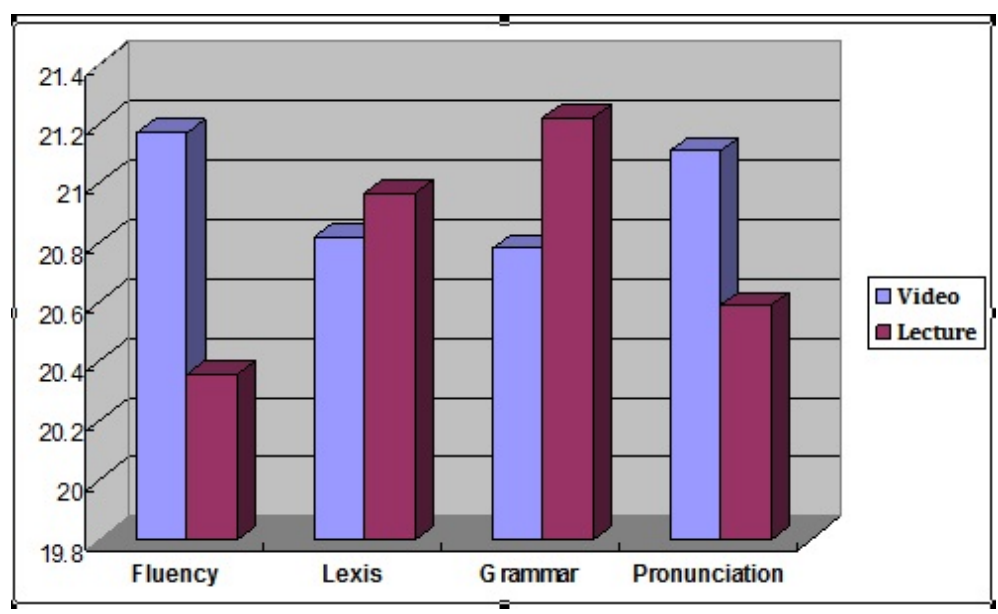

Figure 1. Adjusted means of posttest oral skill scores.

\subsection{Participant Confidence}

To answer the second research question: "Does synchronous videoconference with native English speakers help Chinese pre-service English teachers become more confident in teaching English language", an attitudinal survey was administered to all participants at the end of the treatment to look into participants' confidence level in eight aspects of teaching English language in future. Participant responses to each survey item were analyzed using independent-samples $t$-test. The results are displayed in Table 3, and Figure 2.

The independent-samples $t$-test on the survey responses revealed no significant difference between the experiment group and control group on all the aspects of student confidence in teaching English language except for "Using a variety of assessment strategies". The descriptive statistics further specified that though no significant difference was found between groups on seven of the eight measures, the experiment group had somewhat higher ratings than the control group on all eight measures. The results may suggest that the treatment might have certain positive influence on participants' confidence in teaching English language. The insignificant statistic values might partly result from short treatment (10 weeks) and low frequency of the treatment (once a week).

\section{Discussion}

With ever-increasing pace of multiculturalism and globalization, China as well as other EFL countries is encountered with the challenge of raising the English proficiency of its citizens so that they can be more competitive in world market. Responding to the call of the $21^{\text {st }}$ century, English has become a required subject from elementary school to college in Chinese education system. However, short of qualified English language teachers and limited authentic English learning environment make it harder for Chinese EFL learners to learn the language in a meaningful and effective way.

The data-based findings of this study support the literature that synchronous videoconference with native English speakers has positive impacts on EFL learners' oral skills. The findings also expanded the literature by specifying that synchronous videoconference with native English speakers is most effective on EFL learners' English pronunciation as well as oral fluency and coherence. It seems that English language instruction conducted in traditional classroom setting by native Chinese instructors works better in helping Chinese EFL learners with their grammatical competence, which is in agreement with most anecdotal evidence that Chinese EFL learners have good command of English grammar and always have better performance in grammar tests, such as in TOEFL and GRE grammar section. Given the fact that Chinese English learners are generally weak in English listening and speaking and that native English speakers are scarce in China, online videoconference with native English speakers is obviously a practical, applicable, affordable, effective and efficient strategy for EFL instruction.

Regarding students' confidence in their English oral skills in relation to teaching English language, the descriptive statistics from the attitudinal survey indicated that the project participants had higher level of confidence than the non participants though not statically significant. One reason for the insignificant difference 
Table 3. Independent-samples t-test on student confidence in teaching English language

\begin{tabular}{ccccc}
\hline DV & $\boldsymbol{t}$ & $\mathbf{p}$ & $\begin{array}{c}\text { Mean } \\
\text { Difference }\end{array}$ & SE \\
\hline How much can you do to get students to believe they can do well in English? & 1.17 & 0.25 & 0.26 & 0.22 \\
How well can you help your students value learning English? & 1.50 & 0.14 & 0.32 & 0.21 \\
To what extent can you use classroom (Spoken) English without great difficulty? & -0.06 & 0.96 & -0.01 & 0.18 \\
To what extent can you effectively teach oral language skills to the students? & 1.07 & 0.29 & 0.30 & 0.28 \\
To what extent can you effectively teach written language skills to the students? & 0.49 & 0.62 & 0.14 & 0.28 \\
How much can you use a variety of assessment strategies in your English class? & 2.12 & $\mathbf{0 . 0 4}$ & 0.53 & 0.25 \\
How well can you help your students understand foreign countries' culture(s)? & 0.24 & 0.81 & 0.07 & 0.29 \\
How well can you teach English using English only? & 1.54 & 0.13 & 0.35 & 0.23 \\
\hline
\end{tabular}

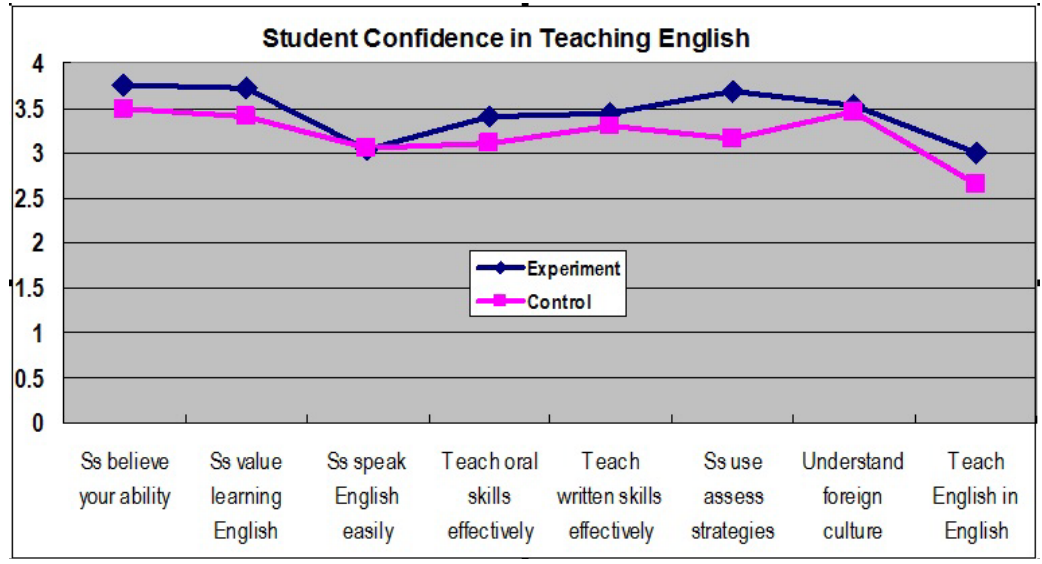

Figure 2. Student confidence in teaching English language.

might be due to the treatment duration and frequency. Another possible explanation might be that the instructor of the control group is an excellent professor who is very well received by her students. Compared to American peer instructors who are undergraduates, this professor is definitely more experienced, skillful and confident in instructional strategies, which might indirectly affect her students' confidence in future teaching. Further research might be needed to provide hard evidence on the issue of correlation between synchronous videoconference with native English speakers and EFL pre-service teachers' confidence in teaching English effectively. It might also deserve an exploration that whether pre-service teachers' English pronunciation and oral fluency are positively related to their confidence in teaching English language.

Education in the 21 st century is embraced by technology and students in the 21 st century are computer savvy. With growing access to Web 2.0 technology, it's of great value to explore more interactive tools for EFL learners so that they are able to learn English language in a more authentic, natural, and meaningful environment. In this sense, the outcomes of this study are promising, and future research in this field will be a worthwhile endeavor.

\section{Acknowledgements}

This paper is part of the research project sponsored by The Returned Overseas Scholar Research Grant provided by Shanxi Department of Education \#[2011] 63.

\section{References}

[1] Sina Education News (2013) An awkward situation: Chinese ranks the second to last in English proficiency. 
http://edu.sina.com.cn/en/2013-10-17/070977415.shtml

[2] Kelm, O. (1992) The use of synchronous computer networks in second language instruction: A preliminary report. Foreign Language Annals, 25, 441-454.

[3] Strever, J. and Newman, K. (1997) Using electronic peer audience and summary writing with ESL students.

[4] Zheng, D., Young, M., Brewer, R. and Wagner, M. (2009) Attitude and self-efficacy change: English language learning in virtual worlds. Journal of College Reading and Learning, 27, 205-231.

[5] Roed, J. (2003) Language learner behavior in a virtual environment. Computer Assisted Language Learning, 16, 155172.

[6] Wu, W., Marek, M. and Yen, L. (2012) Promotion of EFL student motivation, confidence, and satisfaction via a learning spiral, peer-scaffolding, and CMC. International Journal of Computer-Assisted Language Learning and Teaching, 2,22 .

[7] Wu, W.-C.V., Yen, L.L. and Marek, M. (2011) Using online EFL interaction to increase confidence, motivation, and ability. Educational Technology \& Society, 14, 118-129.

[8] Kissau, S. (2012) Perceptions of self-efficacy for two types of second language methods instruction. Computer Assisted Language Learning, 25, 295-317.

[9] Tavani, C.M. and Losh, S.C. (2003) Motivation, self-confidence, expectations as predictors of the academic performances among our high school students. Child Study Journal, 33, 141-151.

[10] Lee, J.H. (2009) Teachers' sense of efficacy in teaching English, perceived English language proficiency, and attitudes toward the English language: A case of Korean public elementary school teachers. PhD Dissertation, The Ohio State University. 